\title{
Allocative Efficiency Analysis of Capsicum Cropping System under Tunnels
}

\author{
HINA FATIMA*1 ${ }^{1}$, LAL K ALMAS ${ }^{2}$ AND BUSHRA YASMIN ${ }^{3}$ \\ Department of Economics ${ }^{1}$, Department of Agricultural Sciences ${ }^{2}$ and Department of Economics ${ }^{3}$ \\ Mohammad Ali Jinnah University, Karachi ${ }^{1 *}$, West Texas A \& M University, Canyon ${ }^{2}$ \\ , Fatima Jinnah Women University, Rawalpindi ${ }^{3}$ ) \\ Department of Economics, Mohammad Ali Jinnah University, Karachi
}

PAKISTAN $^{1,3}$ USA $^{2}$

\begin{abstract}
The focus of this study was to analyze the allocative efficiency of the capsicum cropping system under tunnels. The data is collected from those farmers that were cultivating the capsicum crops under the tunnels in Pakistan. Cultivation of the crops under tunnels has a rising trend in Pakistan. The sample size was around 150 capsicum farms. The Stochastic Frontier Analysis (SFA) was used to examine the allocative efficiency of capsicum farms in Pakistan. The result of the study demonstrated that the average allocative efficiency of capsicum cropping systems under tunnels in Pakistan was around 65\%. Around 35\% of allocative inefficiency is present in the capsicum cropping system. Allocative inefficiency can be reduced by removing the mismanagement practices regarding the utilization of farm resources. It is linked with reallocating inputs or changing the input combination used, to achieve an optimum level of capsicum output at a given level of input prices. Hence, the objective of adoption of advanced farm technologies along with balanced application of farm inputs will result in higher farm productivity and allocative efficiency. Hence, it is recommended that to achieve the best possible capsicum production with a minimum cost of newly opted farm technology can be beneficial if farmers have improved advanced farming skills, trainings and know-how regarding the balanced inputs application under tunnels.
\end{abstract}

Keywords: - Allocative Efficiency (AE), Cobb-Douglas (C-D), Capsicum, Tunnels, High-Tech, Pakistan Received: January 6, 2021. Revised: April 21, 2021. Accepted: April 30 2021. Published: May 7, 2021.

\section{Introduction}

Agricultural sector in developing part of the world is sustained underdeveloped, even though the economies of these countries highly depended on the agricultural sector. According to [1] approximately 70 percent of the LDCs labor force engaged in the agricultural sector and this sector's contribution of Gross Domestic Product (GPD) is around 30 to 60 percent. Typically, the agriculture sector of LDCs is based on horizontal expansion farming scheme (i.e., Increase in farm output by increasing the land under cultivation, etc.) and this is the major cause of low productivity and underdevelopment of the agriculture sector of LDCs. This way of farming is not desirable due to two reasons. First, due to the rapid growth of population, it is difficult to overcome the issue of food security of LDCs. Second, this kind of farming in the future might be resulted in natural resources degradation and environmental hazards.

According to [2] around 1.2 billion populations around the world are breathing in poverty and malnourished. Around $90 \%$ of the population out of 1.2 billion deprived people were existed in Africa and South Asian countries. Explicit policy formulation is required for dealing with low output in developing countries. Compared to Sub-Sharan African countries the south Asian countries adopted the improved farm technologies quite rapidly. Due to this reason, the crop yield in sub-Sharan African countries is stagnant and lower than south Asian countries. According to [3] the difference in adoption of advanced technologies is because of lack of research related activities and investment in agricultural development.

Since we have lost about three million hectares of land to urbanization and the population is going to be doubled by 2020 , the urgency of increasing the productivity is on ever rise. Farming of vegetables is commercialized and for this reason it has greater value. Commercial farming focuses on profit making by considering the allocation of internal and external resources. The efficient utilization of inputs is influenced through various types of resources which can bring fluctuations in farm output. Hence it is vital and appealing to analyse reasons for output variation in farming. 
According to [4], transformation in Pakistan's agricultural sector changed the conventional, complementary farm inputs, i.e., seeds, fertilizer, harvesters, sprays, etc. into High Yielding Varieties (HYV) of seeds, commercial fertilizers, and advanced mechanization. These moderations take along the swift optimistic modifications in agriculture sector growth as well as on Pakistan's economy.

[5] articulated that Pakistan's agricultural sector linked to the rest of the sectors of the economy directly or indirectly. Thus, advancement in technical and scientific fields, introduction of new cultivating and harvesting techniques and development of hybrid seed is essential for agricultural and economic development of Pakistan. [6] articulated that in context of agricultural advancement and technology adoption, Government of Pakistan took several initiatives to pull in the progression exertion in the right direction. Through technology transfer programs, government transferred the agricultural linked technology to the farmers. Government of Pakistan also initiated the farmer field schools (FFSs), as without the farmers' involvement, these agricultural technologies are remained unproductive.

Agricultural development is not possible without farm managers upgraded managerial abilities. These can be acquired through firm training and formal and informal education. Furthermore, to enhance the productivity and efficiency of the factors of production, farm manager's education played dynamic role. An educated farmer has more ability to select the right quantity of inputs, per crop requirements. According to [7], education is the key factor to enhance the farm production. Higher education resulted in higher returns for farm managers, especially in the resourceful agricultural system. According to [8], the level of education has highly significant and positive relationship with farm the production.

The major objective of the present study is to examine the allocative efficiency of capsicum cropping system under the tunnels. This analysis would be helpful in finding out that how good Pakistani farmers are in adoption of new farm technologies. At Some Point, even though the farmers have the access to the modern farm technologies. Yet the mismanagement and lack of skills to utilize accessible high-tech inputs result in dismal growth in farm sector. Hence, current study evaluates the allocative efficiency of sampled farmers those who opted to cultivate the capsicum crop under controlled environment by using the tunnels.

\section{Materials and Methods}

Data were collected from the Faisalabad Division of Pakistan by using the questionnaire regarding offseasonal cropping systems under tunnels. Around 1000 growers were cultivating the capsicum crop under the tunnels in the study area. Out of 1000 farmers, 150 farmers interviewed that were cultivating the capsicum crop under the tunnels by using the purposive sampling technique. Most of the questions were about socio-economic factors and production and cost practices under the tunnels. A detailed questionnaire was developed. Before collecting the data with the help of questionnaire, pre-pilot and pilot survey has been done.

Prediction of economic theory points out that the price for output corresponds to minimum cost of production with the given set of input prices and technology. If buyers and sellers act in competitive manner, purchasing cost function will become $\mathrm{C}$ (yi, pi), representing minimized cost of producing $y_{i}$ at input prices pi.

Frontier models not only used technological frontiers whereas uses reference technology. Cost inefficiency occurs if the cost is not lowered with respect to output. If efficiency has the value of one, then the agreement is on the frontier whereas more than one value shows contract above frontier referring to greater decease in cost.

Two major techniques are generally employed to measure the productivity and efficiency analysis of the agricultural sector, namely, Stochastic Frontier Approach (SFA) and Data Envelopment Approach (DEA). The SFA is parametric technique and based on regression analysis, among output and inputs. The DEA is a non-parametric approach and originated from mathematical programming of the linear piecewise function. Existing study used the SFA technique by following the work of Coelli et al. (2005)

The model for the cost frontier of bitter gourdcapsicum cropping system in its general form can be written as:

$$
\begin{aligned}
& E_{i} \geq E\left(P_{1 i}, P_{2 i},\right. \\
& \left.\leftrightarrow P_{3 i}, \ldots, P n_{i}, Q_{1 i}, Q_{21}, Q_{3 i}, \ldots, Q m_{i}\right)(1)
\end{aligned}
$$

Where $E_{i}$ illustrates the perceived cost of each farm, on the other hand, $P_{n i}$ is the input price of $\mathrm{n}^{\text {th }}$ input and $Q m_{i}$ shows the output of each farm. In order to 
estimate the cost frontier of bitter gourd-capsicum cropping system, it is compulsory to realize the properties of cost minimization solution. Such as homogenous of degree one, non-negative, concave, and non-decreasing in farm input prices and output. To estimate the bitter gourd-capsicum cropping system cost frontier model, this study used the CobbDouglas (C-D) functional form. First, this study opted the Translog functional form but due to the problem of extreme multicolineartity, Translog functional form is not desirable for the analysis of current data at hand. Hence, C-D cost frontier model is finally recommended after the estimation of all required diagnostic regarding functional form.

$$
\begin{aligned}
\ln E_{i}=C_{0} \rightarrow+ & \sum_{n=1}^{N} C_{n} \ln P_{n i} \\
& +\sum_{m=1}^{M} C_{m} \ln Q_{m i}+v_{i} \\
& +u_{i}(2)
\end{aligned}
$$

At this juncture, the term $v_{i}$ is a random and symmetric variable. It symbolizes the statistical noise and estimate errors in the given model. On the other hand, the term $u_{i}$ represents the factors of inefficiency, which is on-negative.

In order to satisfy the above-mentioned properties of cost minimization, the $\beta_{\mathrm{n}}$ is should be non-negative such as:

$$
\sum_{n=1}^{N} C_{n}=1 \text {. (3) }
$$

Henceforward, after imposing the constraint on bitter gourd-capsicum cost function, this constraint of homogeneity which is given in equation no. (4) is substituted in equation no. (5). Which is as follows:

$$
\begin{gathered}
\ln \left(E_{i} / P_{N i}\right)=C_{0}+\sum_{n=1}^{N-1} C_{n} \ln \left(P_{n i} / P_{N i}\right) \\
+\sum_{m=1}^{M} C \ln Q_{m i}+v_{i}+u_{i}(4) \\
\ln \left(E_{i} / P_{N i}\right)=X_{i}^{\prime} C+v_{i}+u_{i}(5)
\end{gathered}
$$

In order to fulfil the necessary condition of normalized cost frontier function, each input price variable in the cost function bitter gourd-capsicum cropping system equation has been divided by the NPK price.

Where $\mathrm{C}_{\mathrm{i}}$, is total cost of production of capsicum crop, $\mathrm{p}_{\mathrm{ni}}$, is price of inputs e.g., price of capsicum seeds, price of fertilizer (NPK), price of pesticides, price/cost of labor, price of farmyard manure, land preparation cost, total cost on tunnels and $y_{\mathrm{mi}}$ is the total output of capsicum.

$$
U_{i}=\delta Z_{i}+\varepsilon_{i}
$$

This study is also opted the model of inefficiency to find out the socio-economics factors that might have effect on technical efficiency of capsicum production system. In equation no. $6, U_{i}$ represents the technical inefficiency in capsicum production function. The $Z_{i}$ variables characterizes the age of farmers, farmers' experience, farm distance from main market (KM), dummy variable of credit availability, dummy variable of owner-cum-tenant, dummy variable of tenant, dummy variable of tractor ownership, area under capsicum crop (acre) and total number of tunnels (acre).

\section{Result and Discussion}

Before the estimation of capsicum cost frontier model, the third hypothesis are applied to the cost frontier model of the capsicum cropping system. This hypothesis implies that non-normalized capsicum cost frontier model is suitable for the study.

The LR statistics test is used to check the validity of the cost model.

$$
\begin{aligned}
& \text { Likelihood RatioTest }=-2\left[\ln H_{0}-\ln H_{1}\right] \\
& =-2[120.1-195.4] \\
& \begin{array}{ll}
= & 149.8
\end{array}
\end{aligned}
$$

The calculated value of likelihood ratio test statistics is 149.8 , which is greater than the tabulated value of 3.84. Hence, it rejected the null hypothesis of nonnormalized capsicum model. Thus, the normalized cost frontier model is estimated from the capsicum cost frontier analysis.

\subsection{Capsicum C-D Stochastic Cost Frontier Analysis}

Efficiency is a multidimensional concept. It encompasses specifically the concepts of production, cost, price, profit, etc. Production frontier is the maximum quantity of output obtained from a given amount of inputs, while cost frontier shows the minimum cost of production of the output for a given number of prices of inputs. In this study, the Cobb- 
Douglas (C-D) cost function applied to the capsicum cost frontier analysis. Table.1 displays the estimated results of capsicum cost frontier analysis.

The capsicum cost frontier function has the gamma coefficient value around 0.99 and it is significant at the $1 \%$ level. This implies that the $99 \%$ change in the total production cost of the capsicum cropping system is due to differences in the cost efficiencies as shown by the gamma value. This result also suggests that farmers in the data set are cost inefficient meaning that the farmers in the sample have not yet acquired the essential skills that enabling them to select the inputs in optimal combinations. The gamma value shows that capsicum growers can achieve the current output at lower costs, which raises the concern about the use of inputs in proportions to the optimality, related to the relative prices of inputs.

Table.1 Capsicum C-D Stochastic Cost Frontier

\begin{tabular}{llrrr}
\hline Variables & Para & Coeff & Std-er & t-ratio \\
Intercept & $\beta 0$ & 1.509 & 1.214 & 4.191 \\
Output & $\beta 1$ & -0.034 & 0.883 & -0.389 \\
Tunnel cost & $\beta 2$ & 0.020 & 0.098 & 0.210 \\
seed cost & $\beta 3$ & 0.077 & 0.136 & 0.571 \\
FYM cost & $\beta 4$ & 0.316 & 0.057 & 0.553 \\
Pesticide cost & $\beta 5$ & 0.105 & 0.102 & 1.035 \\
Labor cost & $\beta 6$ & 0.189 & 0.036 & 5.144 \\
Land preparation & & & & \\
cost & $\beta 7$ & -0.025 & 0.221 & -0.114 \\
\hline Gamma & & & & 0.999
\end{tabular}

The coefficient of capsicum output is negative and significant at the $5 \%$ level. This negative relationship between output and total cost of production demonstrates the increasing returns-to-scale in this study. This result points out that the farmers can minimize production cost by using the farm inputs in optimal proportions given the input prices. This result also illustrates that increase in the cost efficiency among the capsicum farmers would also result to higher farm profit in the study area.

The coefficient of cost of tunnels is positive and highly significant. This highly significant value of cost of tunnels estimate highlights its importance in the cost structure of the capsicum cropping system farms in the study area. The results revealed that as the number of tunnels increases, it would subsequently increase the cost of production of the capsicum cropping system. If the cost of the tunnel is more than the price of output, then alternatively it will increase the cost of production by increasing the number tunnels in capsicum farms.

The coefficient of seed cost is negative and statistically significant at the $5 \%$ level. Likewise, the farmers using improved seed varieties have a higher probability of being cost efficient compared to those farmers who use traditional seed varieties, other factors being held constant. This finding can be explained by the fact that the use of improved seeds translates into an improvement in technical efficiency and resultantly an improvement in cost and economic efficiency. According to [9] and [10] inadequate supply of improved seed varieties resulted in lower farm productivity and higher cost of production.

The coefficient of cost pesticide spray is positive and insignificant. Thus, the pesticide spray relationship with total cost of production is unclear in the capsicum cropping system. It might be due to the fact that farmers are not much informed about the applicable application of pesticides when capsicum crop is cultivated under the controlled environment. The coefficient of labor cost is positive and highly significant at the $1 \%$ level of significance. The result indicates that number of labor hour has a significant effect on the cost function of sampled capsicum farms. This result is in accordance with the studies of [11], [12] and [13].

The land preparation procedures play a vital role in capsicum tunnel farming. The coefficient of land preparations cost is positive and significant at the 1 $\%$ level of significance. This result indicates that an increase in the number of land preparation practices resulted in a corresponding increase in the cost of production of the capsicum cropping system.

The results of the farmyard manure (FYM) on the total cost of production of the capsicum cropping system are positive and highly significant at the $1 \%$ level of probability. This result suggests that an increase in the application of farmyard manures leads to the subsequent increase in the cost of production of the capsicum cropping system farms included in the data set.

\subsection{Cost Inefficiency Model of Capsicum Cropping System}

Table 2 represents the factors that may influence on the allocative efficiency of capsicum cropping system farms of the study area.

In capsicum cost inefficiency model, the coefficient of education is positive and significant. This is the contradictory to the findings of [14], [15], [16] and 
[17]. Although this result is in line with the findings of [18].

The reason behind the positive and significant sign either farmers prefer more non-formal education compared to formal education or most farmers' dependent upon their years of experience to realize the allocative efficiency other than formal education. On the other hand, education plays fundamental role in application of inputs and farm management. This may be due to this fact education effects technical efficiency more compared to the allocative efficiency.

Age of farmer and inefficiency in most of the cases have the positive relationship. The coefficient of age is another positive and highly significant variable implying that efficiency increases with the age of the farmer. This is contradictory to the findings of [15], [11], [17] and [16].

Table. 2 Cost Inefficiency Model of Capsicum Cropping System

\begin{tabular}{lllll}
\hline Variables & Para & Coeff & Std-er & t-ratio \\
Farmers' age & $\delta 1$ & -0.002 & 0.0009 & 2.54 \\
$\begin{array}{l}\text { Farmers' } \\
\text { education }\end{array}$ & $\delta 2$ & 0.015 & 0.003 & 4.52 \\
$\begin{array}{l}\text { Distance from } \\
\text { main market }\end{array}$ & $\delta 3$ & 0.0001 & 0.0005 & 0.25 \\
$\begin{array}{l}\text { Credit } \\
\begin{array}{l}\text { Owner-cum- } \\
\text { tenant }\end{array}\end{array}$ & $\delta 4$ & -0.033 & 0.027 & 1.24 \\
$\begin{array}{l}\text { Tenant } \\
\begin{array}{l}\text { Tractor } \\
\text { ownership }\end{array}\end{array}$ & $\delta 6$ & 1.037 & 0.042 & 24.23 \\
$\begin{array}{l}\text { Operational } \\
\text { holding }\end{array}$ & $\delta 7$ & -0.053 & 0.026 & 2.046 \\
$\begin{array}{l}\text { Total.no. } \\
\text { Tunnels }\end{array}$ & $\delta 8$ & 0.1000 & 0.010 & 9.61 \\
\hline
\end{tabular}

These studies reported that the older a farmer becomes, the more he or she finds difficult to combine the available technology. As the older farmers in most of the cases are hesitant to opt the advance farm technologies as compared to younger farmers [21, 22]. Although the studies of [14] and [19] reported the findings like the present study. Most of the farmers of the capsicum cropping system are middle aged. But up to a certain threshold, and after that, this probability starts decreasing pointing towards the fact that experience in farming plays an important role in the reduction of production costs. The coefficient of access to credit holds the negative sign. Agricultural credit is important as it influences farming productivity and increases input utilization efficiency. Allocative efficiency at a certain input and output price, increases productivity, which is caused by credit support. But it is insignificant. This result is in line with the finding of [20]. Hence, the influence of access to credit on elective is quite uncertain on the capsicum cropping system of the study area.

Furthermore, the coefficients of tenant and owner cum tenant are positive and highly significant at the $1 \%$ level of significance. These results show that those farmers owned the farmers have a higher probability of being allocatively efficient than those with the tenant and the owner cum tenant in the study area. The results revealed that having own farm enables the farmer to fully utilize the production capacities of the used inputs and avoiding their under-utilization.

The tractor ownership coefficient revealed the negative and significant relationship with allocative inefficiency. This result is according to the expectation. The ownership of tractor composes the farmers to do with time farm practices as much as considered necessary during the cultivation and harvesting season. The tractor owned farms not only set aside the cost of hiring the tractor but also execute the land preparation and other farm operation activities on fellow farmers' farm to charge the rental fee. Thus, the tractor ownership, positive influences on the allocative efficiency of capsicum cropping system farms under the tunnels.

The coefficient of operational holding under the capsicum cropping system is positive and statistically significant at the $1 \%$ level. This result depicts that farmers should keep in mind the demand and supply forces of specific crops. Increasing the operational holding for the specific crop without the prior knowledge regarding crop demand resulted in lower crop price, lower profitability, and resultantly higher cost of production. Hence, in case of a capsicum cropping system, increasing the operational holding negatively affect the allocative efficiency of the study area farms.

The coefficient of number tunnels ' per acre is negative and statistically significant at the $1 \%$ level. This result implies that as the number of tunnels increases, it would correspondingly increase the allocative efficiency of capsicum farms in the study area. If the cost of per tunnel is more than the price of capsicum output, then alternatively it will increase the cost of production by increasing the number tunnels in capsicum farms[23,24].The present study revealed the negative relationship in between number of tunnels and allocative efficiency. Hence, it shows 
that as number of tunnels increases the allocative efficiency in capsicum cropping system improved.

\subsection{Allocative Efficiency Analysis of Capsicum Cropping System}

Figure.1 displays the estimated allocative efficiency of the capsicum cropping system farms under tunnels. Allocative efficiency frequency distribution ranges from below 0.20 to above 0.90 . In case of capsicum cropping system around $44 \%$ of the allocative efficiency lies within the range of 0.20 to 0.60 . Around $18 \%$ and $35 \%$ of capsicum farms' allocative efficiency ranged from 0.61 to 0.80 and 0.81 to above 0.90 , respectively.

The mean allocative efficiency is about 0.65 . Hence, allocative efficiency analysis points out the presence of allocative inefficiency in the capsicum cropping system. The result of allocative efficiency analysis revealed that specifically, through input reallocation, capsicum farms can decrease input consumption around $35 \%$ compared to their costs on the production frontier. If the input costs can be decreased 25 to $35 \%$, farm profits of capsicum growers will also increase. This result depicts that farmers could minimize the use of inputs and cost of improved management practices and efficient utilization of inputs. Most of the farmers in the study area, operating the tunnel farming by having the training from their fellow farmers instead of any agricultural institute.

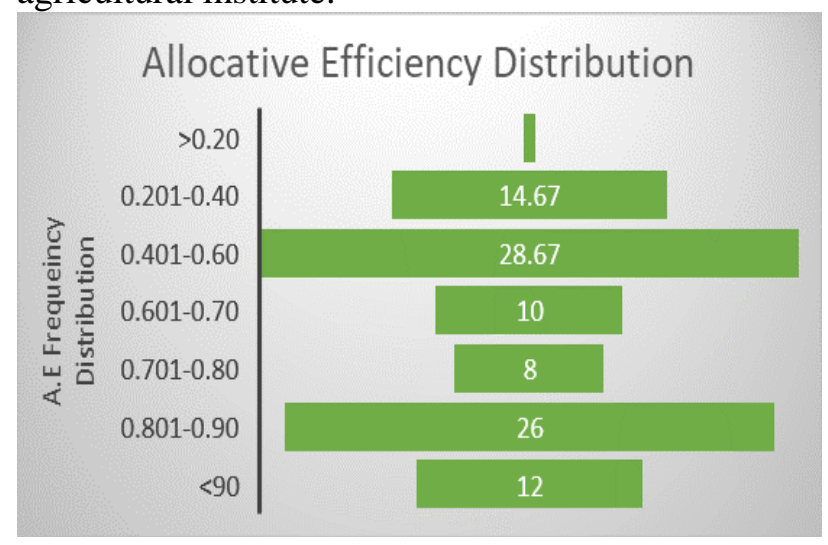

Figure.1 Allocative Efficiency Distribution of Capsicum cropping System.

Due to the mismanagement of farm resources/inputs, the cost of growing the capsicum crop has been increased by around $35 \%$. Hence, by improving the farm management practices, skills, formal education, farmers can get the same level of capsicum output by reducing the $35 \%$ cost of production. The excessive use of farm inputs such as fertilizers negatively affects soil fertility. The unnecessary use of pesticides sprays impact on crop quality and increased the cost of production. Thus, the removal of mismanagement farm practices and reallocation of farm resources will enhance the capsicum output at the optimum level. Prior studies of $[25,26]$ estimated the technical efficiency of capsicum cropping system and other crops found the technical inefficiencies in the production process of different cropping systems. Hence, it is needed that farmers should apply the farm inputs in a way that farmers can get most of the benefit and profitability by applying minimum farm resources on one hand and reduced cost of production and enhanced production on the other hand.

\section{Conclusion}

The major reasons, why capsicum farmers turn out to be dissuaded after opting for the latest technologies as farmers have slight knowledge regarding the use of selected farm technologies, in most of the cases. The most part of the farmers in the study area take up the high-tech technologies and tunnel farming by following the fellow farmers. And the irony is if farmers are emulating/following those farmers, who himself/herself does not have the complete knowledge of the opted technology, then that halflearned knowledge will be transferred to all the farmers of that specific area, and consequently will impact negatively towards the efficacy of adopted farm technology. Most of the farmers prefer the suggestions of fellow farmers over meeting with the extension centre staff or agricultural experts from agricultural institutions. Most of the time, these preferences lead to erroneous information, inappropriate selection of farm inputs and technologies that ultimately leads to massive farm losses in the study area.

Thus, each time, farmers are going to select new technology, public/private research institutes should provide their best possible expertise as a frontline farm worker. Opting the high-tech technology, and skilled to generate the best out of it is an art that can be achieved by incessant learning while administering through the well-learned argic-experts and research institutes. The focus of agricultural policy should recognize the efficiency gains as a source of improving productivity and profitability and thus poverty for the sizeable part of Pakistan's agricultural sector.

\section{References:}

[1] Koroma, S.2007. Globalization, Agriculture and Least Developed Countries, United Nations Ministerial Conference of the Least Developed Countries, Istanbul 9-11 July.

[2] Bravo-Ortega, C., Lederman, D. 2005. Agriculture and National Welfare around the World: Causality and International 
Heterogeneity since 1960, In: Policy Research Working Paper 3499, World Bank, Washington, DC.

[3] Pardey, P.G., James, J.S., Alston, J., Wood, S., Koo, B., Binenbaum, E., Hurley.T, and Glewwe.P.2007. Science, Technology and skills, Background paper for the World Bank's World Development Report 2008., St. Paul, Rome, and Washington D.C.: University of Minnesota, CGIAR Science Council and World Bank

[4] Looney, E.R. 1999. Private Sector Investment in Pakistani Agriculture, International Journal of Development Studies., Vol.15, No.2, pp. 188204.

[5] Amjad, R. (2009)., Key Challenges Facing Pakistan Agriculture: How Best can Policy Makers Respond? A Note. Paper presented in the GDN 11th Annual Conference. held on 1618 January 2010 at Prague, Czech Republic

[6] Javed, H.Z., Farooq, M., and Ali, H. 2010. Technology Transfer and Agricultural Growth in Pakistan, Pakistan Journal of Agricultural Sciences, Vol.47, No.1, pp. 28-87.

[7] Welch, F.1970. Education in Production, International Journal of Political Economy, Vol.75, pp. 35-39.

[8] Wadud, M.A and White, B. 2000. Farm Household Efficiency in Bangladesh: A Comparison of Stochastic Frontier and DEA Methods, Applied Economics, Vol.32, pp. 166573.

[9] Pakistan, Government of 2012, Planning Commission of Pakistan, Ministry of Planning Development \& Special Initiatives.

[10] Aslam, M. 2016. Agricultural Productivity Current Scenario, Constraints and Future Prospects in Pakistan, Sarhad Journal of Agriculture, Vol.32, No.4, pp. 289-303.

[11] Khan,H and Saeed,I. Measurement of technical, allocative and economic efficiency of tomato farms in Northern Pakistan, International Conference of Management, Economics and Social Sciences, Planetary Scientic Research Centre, Bangkok, pp. 459-468.

[12] Koirala, H.K., Mishra, K.A., and Mohanty. S. 2014. Determinants of Rice Productivity and Technical Efficiency in the Philippines, Southern Agricultural Economics Association, 2014 Annual Meeting, February 1-4, 2014, Dallas, Texas

[13] Mohammad, R., and Saghaian.S. 2014 Technical Efficiency Estimation of Rice Production in South Korea, Southern Agricultural Economics Association, 2014
Annual Meeting, February 1-4, 2014, Dallas, Texas

[14] Ahmad, M., G. C. Mustafa and M. Iqbal. 2002. Wheat Productivity, Efficiency and Sustainability: A Stochastic Production Frontier Analysis, The Pakistan Development Review, Vol.41, pp. 643-663.

[15] Abedullah,B.K and Ahmad.B. 2006. Technical Efficiency and its Determinants in Potato Production Evidence from Punjab Pakistan, Lahore Journal of Economics, Vol.11, No.2, pp. 1-22.

[16] Ali, M., and Hau, V.T.H.2001. Vegetables in Bangladesh: Economic and Nutritional Impact of New Varieties and Technologies, Asian Vegetable Research and Development Center (AVRDC), Tainan, Taiwan

[17] Saddozai, K.N., A. Saboor, A. M. Khan, D. Jan and G. Ali. 2013. Analyzing the Impact of Farmer Field School on Technical Efficiency of Cotton Growers in Southern Districts of PunjabPakistan, Sarhad Journal of Agriculture, Vol.29, No.2, pp. 291-298.

[18] Sadiq, G. H., U. Zahoor, A. Farman, M. Khalid, S. Musawar and K. Inamullah. 2009 Technical Efficiency of Maize Farmers in Various Ecological Zones of AJK, Sarhad Journal of Agriculture, Vol.25, No.4, pp. 606-610.

[19] Ali, S. and Khan, M.2014.Efficiency of Wheat Production in District Peshawar, Khyber Pakhtunkhwa, Pakistan, Sarhad Journal of Agriculture, Vol.30, No.4, pp. 433-441.

[20] Hassan, S., and Ahmad. B. 2005. Technical Efficiency of Wheat Farmers in Mixed Farming System of the Punjab, Pakistan., International Journal of Agriculture and Biology, Vol.7, No.3pp. 431-435.

[21] Fatima, H, Lal. K. A and Yasmin. B. 2017. Production Efficiency Analysis of Capsicum (Bell Pepper) Cropping System under the Tunnels in Punjab, Pakistan, 2017 Annual Meeting, February 4-7, 2017, Mobile, Alabama 252736, Southern Agricultural Economics Association.

[22] Ali, Q., Khan, M.T.I., and Ashfaq. M. 2018. Efficiency Analysis of Off-Season Capsicum/Bell Pepper Production in PunjabPakistan: A DEA Approach, The Journal of Animal \& Plant Sciences, Vol (28), No. (5) pp. 459-468

[23] 23. Erlina., Y. Koestiono, D. Hanani.N, Syafrial. 2019. The Influence of Rubber Price Fluctuation on the Performance of Smallholder Rubber Plantation in Central Kalimantan, Indonesia, WSEAS 
Transactions on Business and Economics, Vol. (16), pp. 130-137.

[24] Heriyanto,. A. 2019. Structures of Revenue, Expenditure, and Welfare of Household Farmers in Kampar Regency, Riau Indonesia, WSEAS Transactions on Business and Economics, Vol (16), pp. 1-8.

[25] Akter, S., Islam M.S., and Rahman,M.S. (2011). An economic analysis of winter vegetables production in some selected areas of Narsingdi district. Journal of Bangladesh Agricultural University. Vol. (9), No (2), pp.241-246.

[26] Naik P.S., Singh. M., and Ranjan. J.K.2017. Impact of Climate Change on Vegetable Production and Adaptation Measures. In: P. Minhas, J. Rane, and R. Pasala (eds) Abiotic Stress Management for Resilient Agriculture. Springer, Singapore

\section{Sources of funding for research} presented in a scientific article or

\section{scientific article itself}

The research in this manuscript has partially been supported by the Ogallala Aquifer Program, a consortium of the USDA Agricultural Research Service, Kansas State University, Texas A \& M AgriLife Research, Texas A \& M AgriLife

Extension Service, Texas Tech University, and West Texas A \& M University.

\section{Creative Commons Attribution}

\section{License 4.0 (Attribution 4.0}

\section{International, CC BY 4.0)}

This article is published under the terms of the Creative Commons Attribution License 4.0 https://creativecommons.org/licenses/by/4.0/deed.en US 